\title{
Physiological Contribution of CD44 as a Ligand for E-Selectin during Inflammatory T-Cell Recruitment
}

\author{
Maria Nácher, ${ }^{*}$ Ana Belén Blázquez, ${ }^{\dagger}$ \\ Bojing Shao, ${ }^{\ddagger}$ Adela Matesanz, ${ }^{\S}$ \\ Colette Prophete, ${ }^{\text {9 } \|}$ M. Cecilia Berin, ${ }^{* \star \dagger}$ \\ Paul S. Frenette, ${ }^{\mathrm{q \| \star *}+\dagger}$ and Andrés Hidalgo*ף\| \\ From the Departments Epidemiology, Atherothrombosis and \\ Imaging," and Vascular Biology and Inflammation, ${ }^{\S}$ Centro \\ Nacional de Investigaciones Cardiovasculares, Madrid, Spain; \\ the Division of Pediatric Allergy and Immunology, ${ }^{\dagger}$ the \\ Immunology Institute, "the Departments of Medicine," and Gene \\ and Cell Medicine, ${ }^{* *}$ and the Black Family Stem Cell Institute, ${ }^{\text {t十 }}$ \\ Mount Sinai School of Medicine, New York, New York; and the \\ University of Oklaboma Health Sciences Center, ${ }^{\ddagger}$ Oklaboma City, \\ Oklaboma
}

Endothelial selectins guide the migration of inflammatory $\mathbf{T}$ cells to extralymphoid tissues. Whereas $\mathbf{P}$ selectin glycoprotein ligand-1 (PSGL-1) functions as the exclusive ligand for P-selectin, it acts in coordination with additional glycoproteins to mediate $\mathrm{E}$ selectin binding. CD44 can act as one such ligand in neutrophils, but its contribution in inflammatory $\mathbf{T}$ lymphocytes remains unexplored. We have used realtime in vivo imaging of the cremasteric and dermal microcirculations to explore the dynamics of leukocyte recruitment, as well as the physiological contribution of CD44 in a model of Th1-driven inflammation. $\mathrm{CD}^{+}$T-cell rolling frequency and kinetics, as well as arrest, were dependent on endothelial selectins and were markedly altered under inflammatory conditions. CD44 extracted from Th1 cells bound to soluble E-selectin in vitro and cooperated with PSGL-1 by controlling rolling velocities and promoting firm arrest. Using several competitive recruitment assays in a delayed-type hypersensitivity model, we show that the combined absence of CD44 and PSGL-1 impairs inflammatory T-cell recruitment beyond that of PSGL-1 alone. Differential expression of leukocyte fucosyltransferases in these cells may account for the differential use of E-selectin ligands relative to neutrophils. Our results identify additional mechanisms by which CD44 modulates the inflammatory response. (Am J Pathol 2011, 178:2437-2446; DOI: 10.1016/j.ajpath.2011.01.039)
The trafficking of $\mathrm{T}$ lymphocytes is regulated by their repertoire of adhesion and chemotactic receptors. Naïve $\mathrm{T}$ cells recirculate through secondary lymphoid organs in search of their cognate antigen, a process facilitated by their specific binding to high endothelial venules through L-selectin, $\beta 2$ integrins, and the chemokine receptor CCR7. Once activated, effector and memory $T$ cells switch their adhesive and signaling repertoire to one that allows immune surveillance of tissues. In particular, skin and inflamed areas are dynamically infiltrated by activated T cells, a process that underlies a number of pathogenic inflammatory diseases. ${ }^{1}$ It is generally accepted that this infiltration is initiated by extravasation from the blood microvasculature through a multistep cascade similar to that undergone by neutrophils, including initial tethering and rolling events followed by firm arrest and diapedesis. ${ }^{2}$ Tethering and rolling are initiated by labile interactions mediated by endothelial $\mathrm{P}$ - and E-selectins (encoded by Selp and Sele genes, respectively) expressed constitutively in the skin microvasculature ${ }^{3}$ and induced in other tissues during inflammation. ${ }^{2}$ Induction of ligands for endothelial selectins is therefore critical for the acquired migrating properties of inflammatory lymphocytes. $^{4}$

Two glycoproteins expressed on Th1 lymphocytes, Pselecting glycoprotein ligand-1 (PSGL-1; encoded by Selplg) and the sialomucin CD43, have been shown to

Supported by a Scientist Development grant from the American Heart Association to A.H. and U.S. National Institutes of Health grant R01 HL69438 to P.S.F (0735165N). A.H. is also supported by a Ramón y Cajal fellowship, a grant (SAF2009-11037) from the Spanish Ministry of Science and Innovation, and by a grant (246655) from the FP7-People-IRG Program. The Centro Nacional de Investigaciones Cardiovasculares is supported by the Spanish Ministry of Science and Innovation and the ProCNIC Foundation.

Accepted for publication January 28, 2011.

Supplemental material for this article can be found at http://ajp. amjpathol.org or at doi: 10.1016/j.ajpath.2011.01.039

Current address of C.P. and P.S.F., Institute of Stem Cell Biology and Regenerative Medicine, Albert Einstein College of Medicine, New York, NY; of A.B.B., Fundación IMABIS, Malaga, Spain.

Address reprint requests to Andrés Hidalgo, PhD, Centro Nacional de Investigaciones Cardiovasculares, Calle Melchor Fernández Almagro, 3, Madrid, 28029 Madrid, Spain. E-mail: ahidalgo@cnic.es. 
mediate E-selectin binding in vivo. ${ }^{5-8}$ Combined deficiency in both PSGL-1 and CD43, however, fails to completely abolish E-selectin binding and infiltration of inflammatory T cells into inflamed tissues, ${ }^{5,7}$ suggesting that additional ligands are expressed. CD44, a glycoprotein expressed on hematopoietic and nonhematopoietic tissues, has been shown to mediate E-selectin binding by human CD34 ${ }^{+}$progenitor cells ${ }^{9}$ and human and murine neutrophils, ${ }^{10}$ but its contribution in other leukocyte subsets, including lymphocytes, is not known. Intravital imaging of inflamed murine microvessels has demonstrated that CD44 mediates the slow rolling motion and receptor polarization of neutrophils, both of which are dependent on E-selectin engagement. ${ }^{10,11} \mathrm{CD} 44$ has been previously recognized as an important receptor for the recruitment of activated T cells through interactions with a number of components of the extracellular matrix ${ }^{12-14}$ and through rolling on hyaluronic acid (HA), ${ }^{15-17}$ which is induced on inflamed microvascular endothelial cells. ${ }^{18}$ Signaling through ligands for E-selectin, including PSGL-1 and ESL-1, has been shown to modulate integrin activity on neutrophils, resulting in reduced rolling velocities, ${ }^{19}$ promotion of firm arrest, ${ }^{20}$ and secondary capture of blood components. ${ }^{21}$ Whether CD44 shares these properties on inflammatory lymphocytes remains unknown.

Generation of functional selectin ligands in hematopoietic cells requires the induction of a set of glycosyltransferases that allow the decoration of protein scaffolds with sialyl Lewis $\mathrm{x}$, an $\alpha 2,3$-sialylated, $\alpha 1$,3-fucosylated tetrasaccharide. ${ }^{22}$ In Th1 lymphocytes, up-regulation of fucosyltransferase 7 (encoded by Fut7) is the rate-limiting step for the synthesis of selectin ligands. ${ }^{23} \mathrm{~A}$ second leukocyte fucosyltransferase, Fut4, is also required for complete selectin ligand synthesis, at least in myeloid cells. ${ }^{23,24}$

We have used real-time intravital imaging techniques and competitive inflammatory models to study the contribution of CD44 as a ligand for E-selectin on inflammatory $T$ lymphocytes. We provide in vivo evidence for cooperation between CD44 and PSGL-1 in selectin-mediated rolling and firm adhesion of Th1 cells on inflamed venules, as well as in the migration of endogenously generated inflammatory $\mathrm{T}$ lymphocytes. Our findings identify additional roles for CD44 in the migration of inflammatory lymphocytes and suggest that leukocytes of the innate and adaptive immune system might use different repertoires of E-selectin ligands.

\section{Materials and Methods}

\section{Mice}

Wild-type C57BL/6 mice were purchased from the US National Cancer Institute. The Cd44-1-, Selplg ${ }^{-1-}$ (N5), Selplg/Cd44 $4^{-1-}$ (N6), Selp ${ }^{-1-}$, Sele ${ }^{-1-}$, Selp/Sele ${ }^{-1-}$, Fut4 ${ }^{-1-}$, and Fut $7^{-1-}$ mouse lines were all in the C57BL/6 background (backcrossed for at least 10 generations, except where the $\mathrm{N}$ number of generations is indicated), and have been previously described. ${ }^{10,21,24}$ Genotypes of all mice were determined by PCR. All animals were housed at the Mount Sinai School of Medicine barrier facility. All experimental procedures involving animals were approved by the Mount Sinai Animal Care and Use Committee.

\section{Preparation of Th1 Cells}

Naiive $\mathrm{CD} 4^{+} \mathrm{T}$ cells were isolated from lymph nodes and spleens using the EasySep Enrichment kit (Stem Cell Technologies, Vancouver, BC, Canada) and cultured on 24-well plates previously coated with $3 \mu \mathrm{g}$ of antibodies against mouse CD3 and CD28 (BD Biosciences, Sparks, $\mathrm{MD}$ ) in media containing $50 \mu \mathrm{mol} / \mathrm{L}$ 2-mercaptoethanol, 5 ng/mL IL-2, 10 ng/mL IL-12 (Peprotech, Rocky Hill, NJ), and $10 \mu \mathrm{g} / \mathrm{mL}$ anti-IL-4 antibody (eBioscience, San Diego, CA). After 2 days, cells were transferred to uncoated wells and cultured for three additional days. Secreted cytokine production [interferon (IFN)- $\gamma$ and IL-4] was tested by ELISA to confirm appropriate polarization toward the Th1 subset for cells of each genotype.

\section{Induction of Delayed-Type Hypersensitivity}

Mice were sensitized by application of $100 \mu \mathrm{L}$ of $2 \%$ $(w / v)$ oxazolone (4-ethoxymethylene-2-phenyl-2-oxazolin-5-one; Sigma-Aldrich, St. Louis, MO) in 4:1 acetone/ olive oil $(v / v)$ to shaved abdominal skin on day 0 . On day 6 , mice were challenged by application of $0.5 \%$ oxazolone or vehicle to the ears ( $10 \mu \mathrm{L}$ per side). In some mice, the left ear was treated with vehicle and the right ear with oxazolone. Mice were analyzed 8 or 24 hours later.

\section{Intravital Microscopy of the Dermal Microcirculation}

Six to 8 hours after oxazolone challenge, mice were anesthetized with $2 \% \alpha$-chloralose and $10 \%$ urethane (SigmaAldrich) in PBS (6 mL/kg), and tracheostomized with PE160 polyethylene tubing (Becton-Dickinson, Franklin Lakes, NJ). Mice were then immobilized with tape, and saline was applied to the dorsal side of the ear, where a coverslip was positioned to keep it in a flattened and horizontal position without disturbing the blood flow. The mouse was covered with a custom-made ventilated plastic box containing a small opening to hold the coverslip in place while allowing access of the microscope objectives to the tissue. Immediately before image acquisition, mice were intravenously injected with $0.5-\mu \mathrm{g}$ phycoerythrinconjugated anti-CD4 (eBioscience), 0.5- $\mu$ g APC-conjugated anti-Gr-1 (BD Biosciences), and 0.1-mg FITC-Dextran (70 kDa; Sigma). Images were acquired with an Olympus BX61WI work station mounted on a motorized $X, Y$ stage (Applied Scientific Instrumentation, Eugene, OR), and fitted with an upright UMPlanFI 20× NA $0.50 \propto$ water-immersion objective (Olympus, Melville, NY). Images were collected with a SensiCam camera (Cooke, Auburn Hills, MI) mounted on a Video Scope image intensifer (VideoScope International, Sterling, VA). Slide- 
Book software (Intelligent Imaging Innovations, Denver, CO) was used for data analysis.

\section{Analysis of Intravital Microsopy Experiments}

Hemodynamic parameters were calculated from digital recordings as described. ${ }^{11}$ To obtain centerline velocities $\left(V_{r b c}\right)$, we divided the distance traveled by the fastest free-flowing cells per frame by 0.117 seconds $(8.5 \mathrm{fps}=$ $117 \mathrm{~ms} /$ frame). Each rolling leukocyte passing through the field of view (length $\sim 100 \mu \mathrm{m}$ ) was counted during 3 minutes, and $\mathrm{CD}^{+}$or $\mathrm{Gr}-1^{+}$leukocyte rolling flux was calculated by dividing $\mathrm{CD} 4^{+} / \mathrm{Gr}-1^{+}$cell rolling flux per minute by the total $\mathrm{CD} 4^{+} / \mathrm{Gr}-1^{+}$cell flux per minute, which was estimated as $\left(\mathrm{CD}^{+} / \mathrm{Gr}-1^{+}\right) \times \mathrm{Vmean} / \pi /\left(\mathrm{V}_{\mathrm{D}} /\right.$ $2)^{2}$, where $\mathrm{CD} 4^{+} / \mathrm{Gr}-1^{+}$is the number of cells of each subset per milliliter of blood, Vmean is estimated as $V_{\text {rbc }} \times 0.625$, and $V_{D}$ is the venular diameter. Adherent fractions were calculated by counting the number of arrested cells (defined as those remaining static for $\geq 30$ seconds) and presented as the percentage of the total $\mathrm{CD} 4^{+}$or $\mathrm{Gr}-1^{+}$cell flux in each venule using the formula shown above. Arrest efficiency is defined as the fraction of rolling cells that arrest on the endothelium, as was calculated by dividing the adherent fraction by the rolling flux fraction for each venule.

\section{Intravital Microscopy of the Cremaster Muscle}

In vitro maturation of the cremasteric circulation was performed and analyzed as previously described. ${ }^{25}$

\section{Adhesion Assays}

Th1 cells were labeled with CFSE (Molecular Probes, Eugene, OR) and incubated with $1 \mu \mathrm{g}$ of rat IgG control or anti-CD44 (clone IM7) antibodies for 15 minutes at $4^{\circ} \mathrm{C}$. After washing, bound primary antibodies were cross-linked by addition of a goat anti-rat IgG (Jackson ImmunoResearch Laboratories, West Grove, PA) for 15 minutes at $37^{\circ} \mathrm{C}$, and cells were plated onto intercellular adhesion molecule 1 (ICAM-1)-Fc (5 $\mu \mathrm{g} / \mathrm{mL}$; R\&D Systems, Minneapolis, MN) coated wells. After incubation for 20 minutes at $37^{\circ} \mathrm{C}$, unbound cells were washed away with warm buffer, and bound cells were quantified using an ELISA reader.

\section{Competitive Homing and Migration Experiments}

For the competitive migration of endogenous inflammatory $T$ cells, we generated chimeric mice by bone marrow transplantation into Ly5.2 wild-type recipients. At least 8 weeks after transplant, mice were treated to induce delayed-type hypersensitivity (DTH), and the differential recruitment of experimental (Ly5.1) and wild-type competitor cells (Ly5.2) in the inflamed ears was assessed by flow cytometry and normalized relative to that present in the blood. Tissue leukocytes were obtained after sequential digestion with trypsin and collagenase IV $(1.6 \mathrm{mg} / \mathrm{mL}$; Worthington Biochemical Corporation, Lakewood, NJ) and were filtered through nylon mesh.
In a separate set of experiments, Th1 cells were generated in vitro from Selplg ${ }^{-1-}$ and double-knockout (DKO) mice and fluorescently labeled alternately with $\mathrm{PKH} 2$ and PKH26 (Sigma). The differentially labeled Th1 cells were injected intravenously in equal numbers into mice challenged 24 hours earlier by application of oxazolone and treated with hyaluronidase (60 $\mathrm{U}$ per mouse). The fraction of differentially labeled Th1 cells within the inflamed ears was estimated 3 hours later by flow cytometry, and corrected using the ratio of the input population. Interchange of PKH2 and PKH26 labeling between Selplg ${ }^{-1-}$ or DKO Th1 cells yielded similar outcomes.

\section{Flow Cytometry and E-Selectin Binding Assay}

Cells were labeled with biotin- or phycoerythrin-labeled anti-CD44 (clone IM7; BD Biosciences), anti-PSGL-1 (clone 4RA10), or control antibodies (all at $10 \mu \mathrm{g} / \mathrm{mL}$ ). Biotinylated antibodies were stained by incubation with Cy5-conjugated streptavidin (Jackson ImmunoResearch). Fluid-phase binding of the E-selectin/lgM chimera to blood leukocytes or CD44 immunopurified on rat IgGcoated beads (M450 Dynabeads; Dynal/Invitrogen) was performed as described previously, with the addition of 5 $\mathrm{mmol} / \mathrm{L}$ EDTA in the control samples. ${ }^{10}$ Using our immunoprecipitation conditions, CD44 appears as the only protein from Th1 lysates that binds to the beads, thus excluding that potential contaminants contribute to selectin binding (see Supplemental Figure S1 at http://ajp. amjpathol.org). On cellular samples, dead cells were excluded by DAPI or propidium iodide staining. Samples were acquired using a FACSCalibur flow cytometer (Becton Dickinson) and analyzed with the FlowJo software (Tree Star, Ashland, OR).

\section{Quantitative Real-Time PCR}

Total RNA from Th1 cells or bone marrow neutrophils was extracted and reverse transcribed as previously described. ${ }^{11}$ The following primers were used for quantitative real-time PCR analysis of the indicated genes: Gapdh, 5'-TTGGCATTGTGGAAGGGCTCAT-3' (forward) and 5'-GATGACCTTGCCCACAGCCTT-3' (reverse); Fut4, 5'-GATATTGGCCAGGCGTCTTAGT-3' (forward) and 5'-CATCCCAACTGGAAAGCAAAA-3' (reverse); Fut7, 5'-GTGCCTCAGTCCACACTCACCATC-3' (forward) and 5'-GGTTAGCACTCAGACGGCAG-3' (reverse). All experiments were performed in triplicate and normalized to Gapdh.

\section{Statistics}

Data are presented as mean \pm SEM. Data were analyzed by unpaired or paired $t$-tests performed with the GraphPad Prism (GraphPad Software, La Jolla, CA) or Excel programs (Microsoft Corporation, Redmond, WA). $P<$ 0.05 was deemed significant. 
A
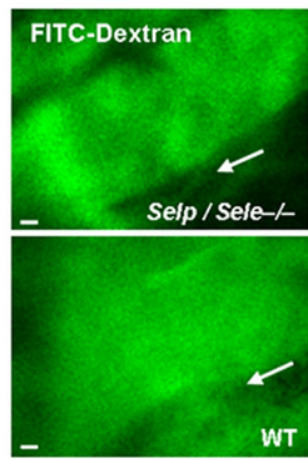
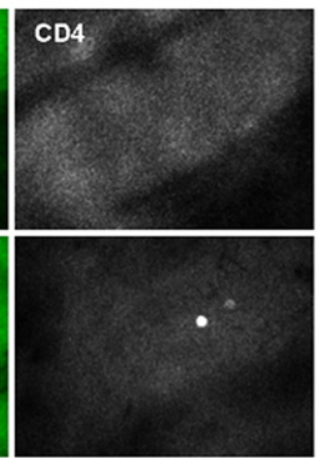

\section{Gr-1}

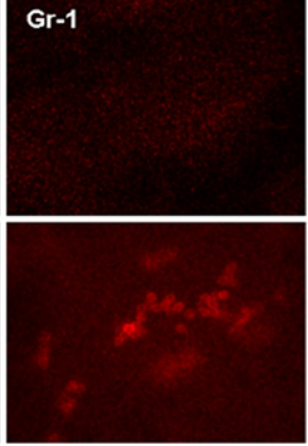

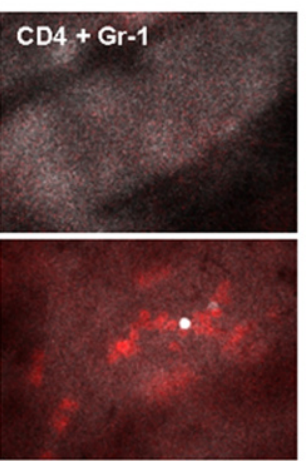

B

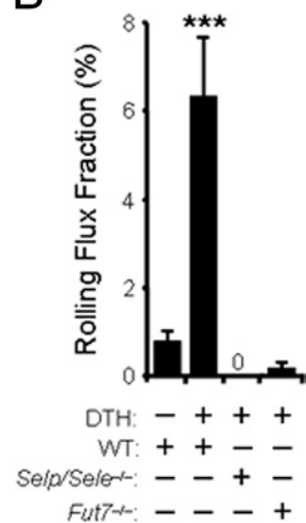

Figure 1. In vivo imaging of inflammatory T-cell recruitment into the inflamed dermal microvasculature. The dermal microvasculature of mice, sensitized with oxazolone and challenged with vehicle (DTH: -) or $0.5 \%$ oxazolone (DTH: +), was imaged 6 to 8 hours after challenge by high-speed fluorescence intravital microscopy (see Supplemental Figure S1 and Supplemental Video S1 at http://ajp.amjpathol.org), after i.v. injection of fluorescent-conjugated antibodies to CD4 or Gr-1. A: Images were acquired in two fluorescence channels to image the behavior of $\mathrm{CD} 4{ }^{+} \mathrm{T}$ cells (Cy3 channel, white) or neutrophils (Cy5 channel, red). FITC-dextran was also injected to delimit the vascular contour (green). Representative images are shown from wild-type (WT) and Selp/Sele-/- mice. Scale bars $=10 \mu \mathrm{m}$. Arrows indicate the direction of flow. B: Rolling of CD $4^{+}$T cells in the dermal microvasculature is induced during inflammatory conditions and is absent in mice deficient for endothelial selectins ( Selp/Sele ${ }^{-1-}$ ) or fucosyltransferase 7 (Fut $\left.7^{\prime-}\right)$. $n=12$ to 27 venules analyzed from four to seven mice per group. ${ }^{* * * *} P$ $<0.0001$ compared to all other groups. DTH, delayed-type hypersensitivity.

\section{Results}

\section{In Vivo Imaging of Inflammatory T-Lymphocyte Recruitment in Dermal Tissue}

We used multichannel fluorescence intravital microscopy to visualize and characterize the dynamic recruitment of inflammatory leukocytes in the mouse dermal microcirculation in vivo (see Supplemental Figure S2 and Supplemental Video S1 at http://ajp.amjpathol.org). We selected the dermal tissue of the ears because well-established protocols exist to induce T-cell-mediated inflammation in this area, 5,6,26,27 and because they are easily accessible for imaging without surgical manipulation and afford a good resolution of superficial vessels by epifluorescence microscopy. ${ }^{3}$ As previously reported, ${ }^{3}$ we have noted a lower blood flow in dermal venules relative to other organs (wall shear rate values of approximately $100 \mathrm{sec}$ onds $^{-1}$ in dermis versus 1000 seconds $^{-1}$ in the cremasteric microcirculation; see Supplemental Tables S1 and S2 at http://ajp.amjpathol.org). Endothelial P- and E-selectins have been shown to be constitutively expressed in dermal venules and to mediate rolling and recruitment of circulating leukocytes in the absence of inflammation. 3,28 The vast majority of these leukocytes are neutrophils that, together with a subset of monocytes, patrol dermal vessels to allow for rapid responses to injury or infection. ${ }^{29,30}$ To discriminate accurately between leukocyte subsets, we injected intravenously very low amounts of fluorescently conjugated leukocyte-specific antibodies at the time of imaging, a procedure that does not alter the dynamic behavior of intravascular leukocytes. ${ }^{31}$ T lymphocytes were thus distinguished by CD4 labeling, and neutrophils by Gr-1 labeling (Figure 1A; see also Supplemental Figure S2 at http://ajp.amjpathol.org). Under noninflammatory conditions, about one-third of passing neutrophils were found rolling on dermal microvessels (see Supplemental Figure S2 at http://ajp.amjpathol.org). In contrast, $<1 \%$ of circulating CD $4^{+}$cells interacted (rolled or arrested) with these vessels (Figure 1B). We next assessed leukocyte rolling under inflammatory conditions by inducing a local DTH response and examining the microcirculation 6 to 8 hours after challenge with oxazolone. Under these conditions, a large fraction of $\mathrm{Gr}-1^{+}$ neutrophils continued to roll, and this was mediated by endothelial selectins, since it was abrogated in mice doubly deficient for both $\mathrm{P}$ - and E-selectin (Selp/Sele ${ }^{-1-}$ mice), or lacking fucosyltransferase VII (Fut ${ }^{-1-}$ mice), an enzyme required for the synthesis of functional selectin ligands ${ }^{3,22}$ (see Supplemental Figure S2 at http://ajp.amjpathol.org). There was also a robust (8.5-fold) increase in the number of rolling $\mathrm{CD}^{+}{ }^{+}$lymphocytes, and this too was abolished in the absence of both endothelial selectins or Fut7 (Figure 1B). This observation agrees with the reported dependence of inflammation in the DTH model both on endothelial selectins and on CD4 ${ }^{+}$lymphocytes. ${ }^{26,32}$ Detailed analysis revealed a marked reduction in the rolling velocities of $\mathrm{CD}^{+}{ }^{+}$cells under inflammatory conditions, and this reduction was entirely mediated by E-selectin, but not P-selectin (see Supplemental Figure S2 at http://ajp.amjpathol.org). This is reminiscent of the behavior of neutrophils ${ }^{3,33}$ and indicates that, despite the marked hemodynamic differences between the dermal microcirculation and that of other tissues, endothelial selectins and their ligands control the rolling kinetics of inflammatory $T$ cells in ways similar to those described for other leukocyte subsets in other tissues. ${ }^{10}$

\section{CD44 Is a Physiological E-Selectin Ligand in Inflammatory $\mathrm{CD}^{+}$Cells}

PSGL-1 and CD43 have been shown to function as Eselectin ligands on inflammatory Th1 lymphocytes; however, the combined absence of both glycoproteins does 
A

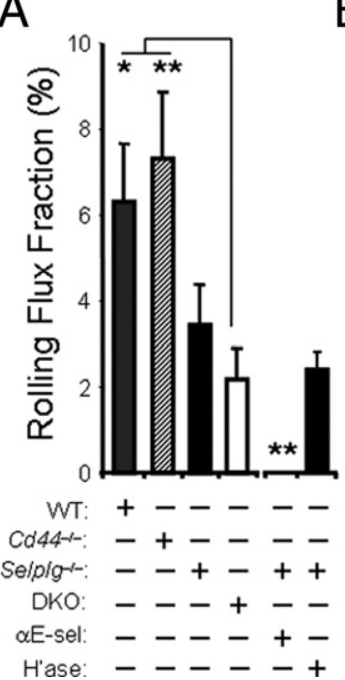

B

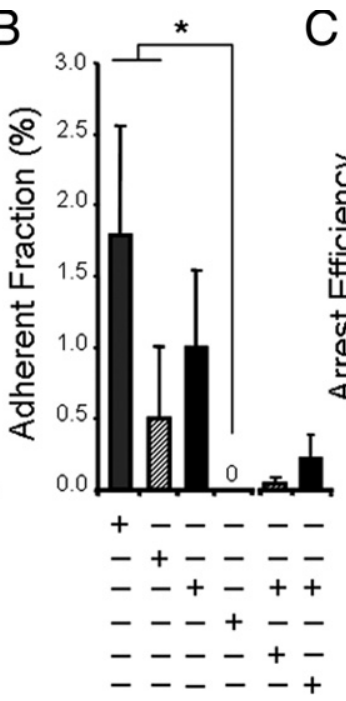

C

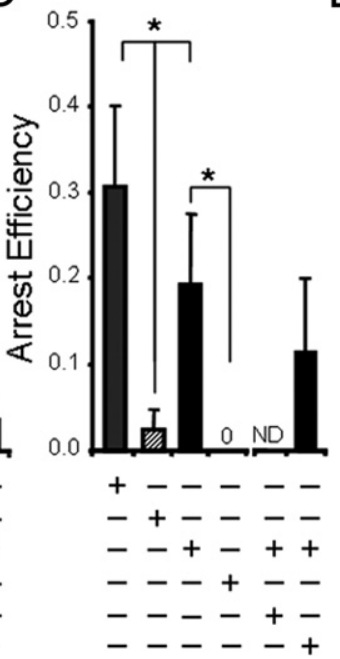

D

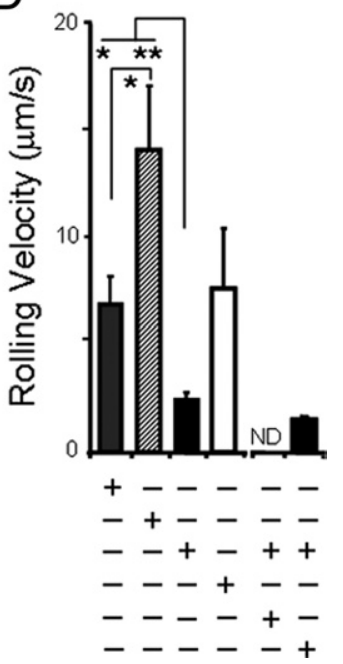

Figure 2. Modulation of selectin-dependent T-cell rolling by CD 44 and PSGL-1. Analysis of the in vivo behavior of CD $4^{+} \mathrm{T}$ cells in the dermal microvasculature 6 to 8 hours after challenge with oxazolone. A: Rolling fractions in mice deficient for CD 44 (Cd44-1-), PSGL-1 (Selplg ${ }^{-1-}$ ), or both (DKO), compared with wild-type (WT) controls. $n=15$ to 25 venules analyzed from six to eight mice per group. Some Selplg ${ }^{-/-}$mice were pretreated with 1 mg/kg of anti-E-selectin antibody (clone 9A9; $\alpha \mathrm{E}$-sel) or 60 units of hyaluronidase (H'ase) before imaging. $n=14$ to 25 venules analyzed from four to five mice per group. ${ }^{*} P<0.05$ between WT and DKO, ${ }^{* *} P<0.01$ between $C d 44^{-1-}$ and DKO as well as between Selplg ${ }^{-1-}+\alpha$ E-sel and all other groups. B: Adherent fractions from the same groups as in A. ${ }^{*} P<0.05$ between WT and $C d 44^{-/-}$compared with DKO. C: Arrest efficiencies in the indicated groups. ${ }^{*} P<0.05$ between $C d 44^{-/-}$and WT, between $\mathrm{Cd}_{44^{-1-}}$ and Selplg ${ }^{-\prime-}$, and between Selplg ${ }^{-/-}$and DKO. D: Rolling velocities of CD $4^{+}$T cells in the indicated groups. $n=15$ to 51 rolling cells analyzed per group. All bars are mean \pm SEM; ND, not determined; numbers indicate values when these are too low for the scale. ${ }^{*} P<0.05$ between WT and $\mathrm{Cd}_{44^{-/-}}$as well as between WT and Selplg ${ }^{-1-} \cdot{ }^{* * *} P<.01$ between $C d 44^{-/-}$and Selplg ${ }^{-1}$

not abolish E-selectin-mediated interactions and recruitment to inflamed tissues, suggesting that additional ligands are expressed. ${ }^{5-7,34}$ We thus sought to use our in vivo imaging approach to identify other glycoproteins present on $\mathrm{CD}^{+} \mathrm{T}$ cells that might be responsible for E-selectin-mediated rolling. The hematopoietic isoform of CD44 binds E-selectin in human and murine neutrophils and CD34+ progenitor cells, $, 9,10$ and is expressed at high levels in a subset of $\mathrm{T}$ lymphocytes that binds E-selectin in vivo ${ }^{7}$ (see Supplemental Figure S3 athttp://ajp.amjpathol. org). We thus hypothesized that CD44 might function as a physiological ligand for E-selectin and contribute to T-cell recruitment to inflamed tissues. We proceeded to analyze the behavior of endogenously generated $\mathrm{CD}^{+}{ }^{+}$inflammatory $\mathrm{T}$ cells in the inflamed dermal microvasculature of mice deficient in CD44 (Cd44-1- $)$, PSGL-1 $\left(\mathrm{Selp} / \mathrm{g}^{-1-}\right)$, or both glycoproteins (Cd44/Selp/g ${ }^{-1-}$ double knockouts; referred to as DKO mice). The rolling flux fractions of $\mathrm{CD}^{+}{ }^{+}$cells were mildly increased in the absence of CD44, and reduced in the absence of PSGL-1, but these differences did not reach significance compared to wild-type animals (Figure 2A). In DKO mice, the rolling flux fraction was reduced beyond that of Selp/g ${ }^{-1-}$ mice, by about $65 \%$ compared to wild-type cells (Figure $2 \mathrm{~A})$. The fraction of $\mathrm{CD}^{+}$cells firmly adhered to the endothelium was comparable in all groups except in DKO mice, where we could not find a single adherent cell in 20 different venules analyzed (Figure 2B). Determination of the arrest efficiencies (the fraction of rolling cells that undergo firm arrest) revealed striking reductions in both groups where CD44 was absent (Figure 2C). Further analysis showed that rolling velocities were markedly increased in $\mathrm{Cd}_{44}{ }^{-1-}$ mice and reduced in the absence of PSGL-1 (Figure 2D), a behavior reminiscent of that of neutrophils. ${ }^{8,10} \mathrm{CD}^{+}$cells from DKO mice displayed a marked increase in rolling velocity compared with those deficient in PSGL-1 alone (Figure 2D), indicating a contribution by CD44 to the control of rolling velocity. In addition, comparison of the rolling fractions between DKO and Selplg ${ }^{-1-}$ mice where E-selectin function was inhibited using blocking antibodies, demonstrated that E-selectin ligands different from PSGL-1 and CD44 exist on $\mathrm{CD}^{+}{ }^{+}$cells (Figure 2A). In contrast, firm arrest was not different between these groups, suggesting an important and specific contribution of CD44 to T-lymphocyte arrest (Figure 2B). Because CD44 contributes to rolling of activated $T$ lymphocytes through binding to hyaluronic acid $(\mathrm{HA}){ }^{15-17}$ it remained possible that engagement of $\mathrm{HA}$, rather than E-selectin, was responsible for the alterations found in mice lacking CD44. To investigate this, we analyzed the behavior of CD4 ${ }^{+}$cells in Selplg ${ }^{-1-}$ mice that had been pretreated with doses of hyaluronidase known to eliminate vascular $\mathrm{HA} .{ }^{10,17,35}$ This treatment did not alter rolling frequency and velocity, and only partially reduced the adherent fraction of Selplg ${ }^{-1-} \mathrm{T}$ cells (Figure 2, A-D), suggesting an $\mathrm{HA}$-independent component in the control of T-cell rolling and arrest by CD44 in vivo.

Although these experiments allowed the analysis of T-cell behavior in a physiological environment, the low frequency of circulating CD $4^{+}$lymphocytes ( $~ 3 \%$ to $8 \%$ in blood, depending on the genotype; see Supplemental Table S1 at http://ajp.amjpathol.org) passing through the dermal microvessels yielded variable values that precluded definitive statistical conclusions. To circumvent this problem, we used a second approach in which inflammatory Th1 lymphocytes, generated in vitro from the various experimental groups, were fluorescently labeled and transferred into wild-type recipients at the time of 
A

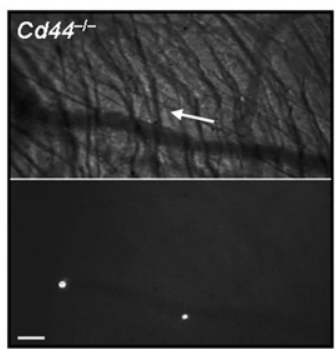

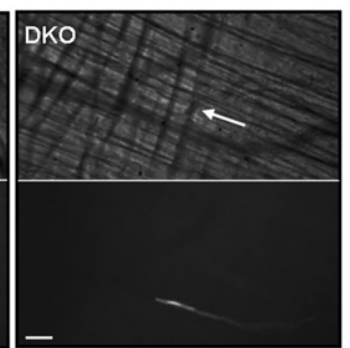

B

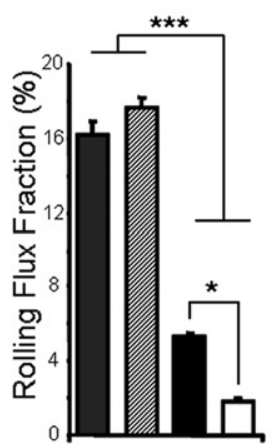

C

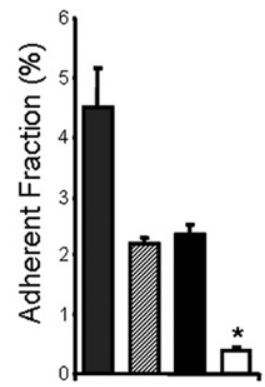

D

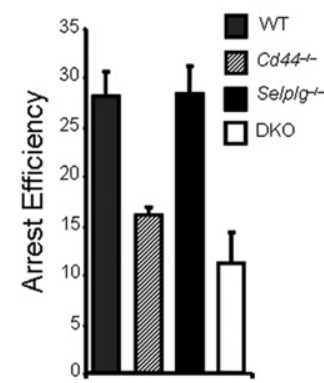

Figure 3. Intravital imaging of in vitro-generated Th1 cells in the cremasteric microcirculation. CFSE-labeled Th1 lymphocytes generated in vitro from wild-type (WT), $C d 44^{-1-}, S_{l} l g^{-1-}$, and DKO mice were injected into wild-type animals in which inflammation of the cremasteric microvessels was induced by intrascrotal injection of TNF $\alpha$. A: Representative brightfield and fluorescent images of rolling (left) and free-flowing (right) Cd44-/- or DKO Th1 cells (white), respectively. Scale bars $=100 \mu \mathrm{m}$. Arrows indicate the direction of flow. B: Rolling flux fractions of wild-type, Cd44 ${ }^{-1-}$, Selplg ${ }^{-/-}$, and DKO Th1 cells. $n=14$ to 27 venules from five to seven mice per group. ${ }^{*} P<0.05$ when $\mathrm{Selplg}^{-1-}$ is compared to DKO, ${ }^{* * * * *} P<0.001$ when the WT and Cd44 ${ }^{-1-}$ groups are compared to Selplg ${ }^{-1-}$ and DKO. C: Adherent fractions of the same groups shown in $\mathbf{B} .{ }^{*} P<0.05$ when DKO is compared to all other groups. D: Arrest efficiencies of the same groups as in $\mathbf{B}$.

intravital imaging. In these experiments, inflammation was induced in the microvasculature of the cremaster muscle by local treatment with $\mathrm{TNF} \alpha$, and the frequency of rolling and firm arrest of passing Th1 cells was assessed by fluorescence videomicroscopy (Figure 3A; see also Supplemental Table S2 at $h$ ttp://ajp.amjpathol.org). Although rolling frequencies did not differ between $\mathrm{Cd} 44^{-1-}$ and wild-type Th1 cells, in those deficient in PSGL-1, it was reduced by $63 \%$ compared with the wild-type group, and by $~ 90 \%$ in the absence of both PSGL-1 and CD44 (Figure 3B). In contrast, the frequency of adherent cells was reduced to a similar extent in $\mathrm{Cd}_{44^{-1-}}$ and Selplg ${ }^{-1-}$ Th1 cells (by $\sim 50 \%$ ), and was reduced by more than 90\% in DKO Th1 lymphocytes compared to wild-type cells (Figure 3C), resulting in reduced arrest efficiency in both groups deficient in CD44 (Figure 3D). These differences did not arise from an altered polarization of naïve lymphocytes into Th1 cells in the different groups, since the polarization into IFN $\gamma$-producing cells was equally efficient for all genotypes (see Supplemental Figure S4 at http://ajp.amjpathol.org). In agreement with the findings made with endogenous CD4 ${ }^{+}$ lymphocytes, treatment of mice with hyaluronidase did not alter the rolling frequency of Selplg ${ }^{-1-}$ Th1 cells, and only partially affected their firm arrest (Figure 4, A and B). Furthermore, the reductions observed in the DKO group were similar to those found with Selplg ${ }^{-1-}$ cells in the presence of a blocking antibody to E-selectin (Figure 4, A and B), suggesting that PSGL-1 and CD44 account for most of the E-selectin binding activity of in vitro-generated Th1 cells under flow. These experiments confirm the trend found for endogenously generated CD4 ${ }^{+} \mathrm{T}$ cells in the inflamed dermal microcirculation (Figure 2), and strongly support a role for CD44 as a physiological E-selectin ligand that cooperates with PSGL-1 in mediating inflammatory T-cell recruitment to inflamed sites.

These in vivo experiments also suggested that CD44 engagement induces signaling events in T lymphocytes that result in enhanced adhesion to the inflamed vasculature, a process mediated by integrins ${ }^{36}$. Indeed, we found that antibody-induced crosslinking of CD44 resulted in a 2.3fold increase in the binding of Th1 cells to recombinant ICAM-1, confirming that CD44-derived signaling modulates T-cell adhesive properties (Figure $4 \mathrm{C}$ ). This modulation is comparable to that induced after crosslinking of PSGL-1 ${ }^{37}$ or by chemokines, ${ }^{38}$ suggesting a cooperation of selectins and chemokines for Th1 cell arrest.

\section{CD44 on Th1 Lymphocytes Binds to E-Selectin in Vitro}

Since the in vivo data obtained so far strongly supported a contribution of CD44 as a ligand for E-selectin on inflammatory $T$ cells, we next directly examined whether CD44 derived from Th1 lymphocytes could bind E-selectin. CD44, which is expressed at high levels on the surface of Th1 lymphocytes generated in vitro (Figure 5A), was immunopurified and immobilized onto beads (see Supplemental Figure S1 at http://ajp.amjpathol.org), and its binding to a soluble E-selectin chimera was assessed by flow cytometry. We found that Th1-derived CD44
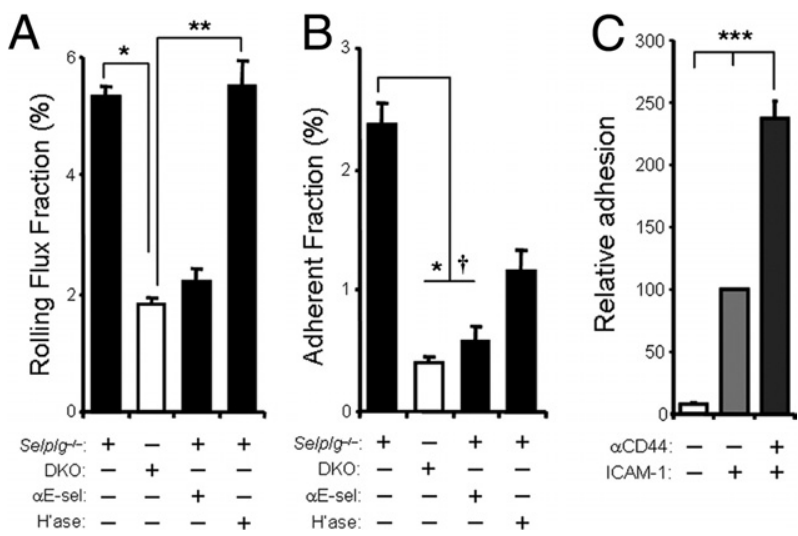

Figure 4. CD44-mediated interactions in vivo are E-selectin dependent and promote Th1 cell adhesion in vitro. The interactions of Th1 cells from Selplg $^{-1-}$ and DKO mice with the cremasteric microvasculature was analyzed as indicated in Figure 3. A: Rolling flux fractions of Selplg ${ }^{-1-}$ and DKO Th1 cells in untreated mice and of Selplg ${ }^{-1-}$ Th1 cells in mice treated with a blocking antibody against E-selectin (9A9) or $60 \mathrm{U}$ hyaluronidase (H'ase). $n=13$ to 27 venules from three to seven mice per group. ${ }^{*} P<0.05,{ }^{* * *} P<0.01$. B: Adherent fractions of the same groups. ${ }^{*} P<0.05$ between $\mathrm{Selplg}^{-1-}$ and DKO, ${ }^{\dagger} P<0.09$ between Selplg ${ }^{-/-}$and Selplg ${ }^{-1-}+\alpha$ E-sel. C: Adhesion of wild-type Th1 cells to recombinant ICAM-1 after cross-linking with control IgG or anti-CD 44 antibodies. One of two similar experiments is shown, each with samples from three different mice. ${ }^{* * * *} P<0.01$ between all groups. All bars represent mean \pm SEM. 

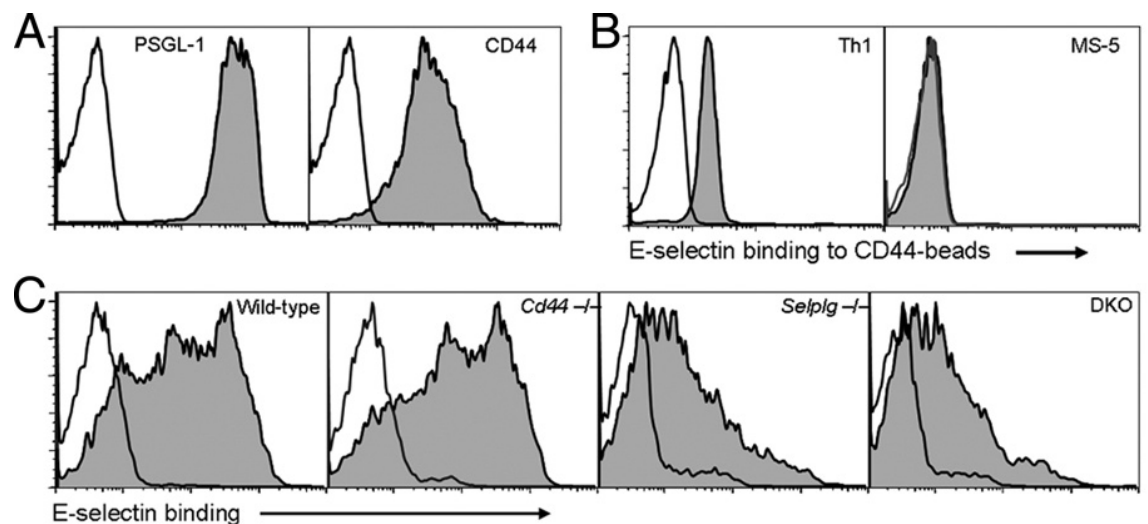

D

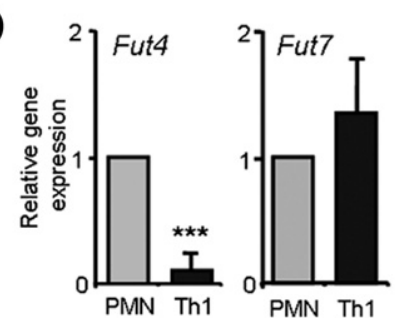

$\mathrm{E}$

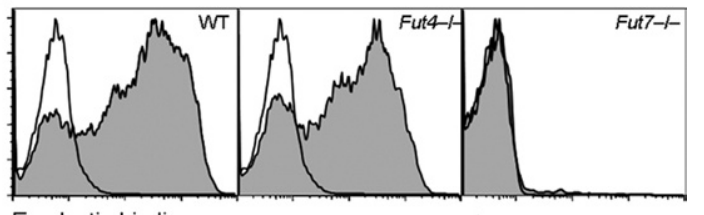

E-selectin binding
Figure 5. Contribution of PSGL-1 and CD 44 to E-selectin binding by Th1 cells. A: Expression of PSGL-1 and CD44 in wild-type in vitro-generated Th1 cells. Open histograms represent staining with isotype controls B: Binding of soluble E-selectin to CD44 immunopurified from wild-type Th1 or MS-5 cell lysates and immobilized onto beads. Empty histograms represent E-selectin binding in the presence of EDTA. Histograms are representative of at least three experiments. C: Binding of soluble E-selectin to Th1 cells generated from wild-type (WT), Cd44 $4^{-1-}$, Selplg ${ }^{-1}$ and DKO Th1 cells. Empty histograms represent E-selectin binding in the presence of EDTA. Histograms are representative of five experiments. D: Relative expression levels of Fut 4 and Fut 7 mRNA in Th1 cells relative to those in neutrophils (PMN). Bars represent means \pm SEM from 3 experiments. ${ }^{\text {***** }} P<$ 0.001. E: Binding of soluble E-selectin to Th1 cells prepared from wild-type, $\mathrm{Fut}^{-/-}$, or Fut $T^{/-}$mice. Histograms are representative of three experiments. bound to soluble E-selectin (Figure 5B), and this binding was specific since it was abrogated in the presence of EDTA or when CD44 was purified from a stromal cell line (MS-5) that does not bind E-selectin despite high levels of surface CD44 (Figure 5B). The binding of soluble Eselectin to intact Th1 cells was not affected by the absence of CD44, with binding comparable between the wild-type and $\mathrm{Cd} 44^{-1-}$ groups, and similarly reduced in the Selplg-l- and DKO groups (Figure 5C). This is in agreement with the well-described and predominant role of PSGL-1 in mediating leukocyte tethering ( ${ }^{8,10}$ and Figures $2 \mathrm{~A}$ and $3 \mathrm{~B}$ ), and supports the notion that CD44 contributes to different stages of the recruitment cascade, such as the control of rolling velocities and transition to firm arrest described above (Figures 2 and 3).

Glycoproteins that function as selectin ligands are expressed in a nonfunctional form in most lymphocytes and several nonhematopoietic cells, and require de novo expression of several glycosyltransferases, including the two leukocyte-specific fucosyltransferases (Fut4 and Fut7), to generate functional selectin ligands. ${ }^{2}$ Because deletion of Fut7 had a profound effect on T-cell rolling (Figure 1B) and Fut4 is reported to be specialized in the modification of only a subset of selectin ligands, ${ }^{39,40}$ we performed expression analysis of their genes in Th1 cells, and compared them to those of neutrophils, a leukocyte subset in which CD44 deficiency yields only a subtle phenotype in cell arrest. ${ }^{11}$ Quantitative PCR analysis showed that Fut4 mRNA levels were indeed very low in Th1 cells, whereas Fut7 levels were comparable to those found in neutrophils (Figure 5D; see also Supplemental Figure S5 at http://ajp.amjpathol.org). This correlated with the unaltered binding of soluble E-selectin to Fut4 ${ }^{-1-}$ Th1 cells and the complete absence of binding to Fut $7^{-1-}$ Th1 cells (Figure 5E). This suggests that Fut7 is the major, if not the only, functional fucosyltransferase in Th1 lym- phocytes and drives the maturation of the E-selectinbinding form of CD44.

\section{CD44 Cooperates with PSGL-1 to Mediate the Recruitment of Inflammatory T Cells in Vivo}

To determine the contribution of CD44 during the physiological recruitment of inflammatory $T$ lymphocytes, we used a competitive DTH approach in which Ly5.2 wildtype cells were used as reference to assess the relative migratory capacity of Ly5.1 gene-deficient cells into the inflamed tissues of Ly5.2 wild-type recipient mice (Figure 6A; see also Supplemental Figures S6 and S7 at http://ajp.amjpathol.org). This approach presents several advantages over noncompetitive models: first, it measures the recruitment of endogenously generated inflammatory $\mathrm{T}$ cells in a selectin-dependent model of DTH; second, since CD44 and PSGL-1 can both be expressed in the vasculature, the use of wild-type recipient mice prevents confounding influences of the endothelial phenotype; and third, the presence of an internal control (Ly5.2 wild-type cells) in the blood and inflamed areas of the same animal yields a more accurate estimate of their relative trafficking abilities. Using this approach, we found that the absence of PSGL-1 from activated T cells reduced their migration to the inflamed tissue, whereas the absence of CD44 alone had no effect (Figure 6A). Combined deficiency in both PSGL-1 and CD44 significantly reduced $\mathrm{T}$-cell recruitment compared with wildtype and $\mathrm{Cd} 44^{-1-}$ cells, and to a greater extent than the absence of PSGL-1 alone, although this difference was not statistically significant $\left(43 \%\right.$ reduction in Selp/g ${ }^{-1-}$ cells versus $59 \%$ in DKO cells; Figure 6A). To compare the migratory capacity of Selplg ${ }^{-1-}$ and DKO cells more directly, we performed two additional sets of experiments 

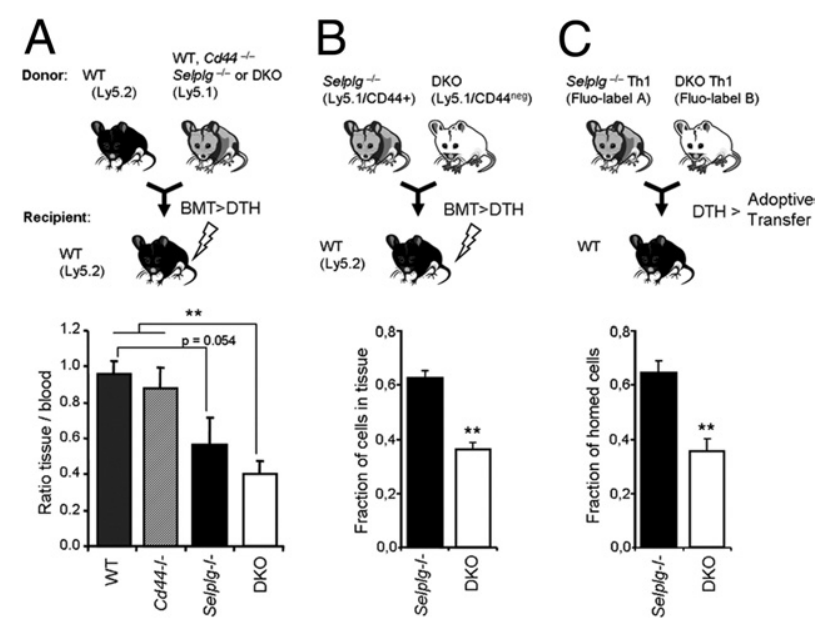

Figure 6. Inflammatory T-cell recruitment in a model of delayed-type hypersensitivity. A: Chimeric mice were generated by bone marrow transplantation (BMT), and the efficiency of migration to the inflamed ears of genetargeted inflammatory TCR $\beta^{+}$lymphocytes relative to wild-type competitor cells was analyzed 24 hours after oxazolone challenge. Bar graphs show the relative frequencies (inflamed tissue/blood ratios) of experimental (Ly5.1) compared to wild-type (Ly5.2) competitor T lymphocytes in the inflamed tissue (see Supplemental Figure S7 at http://ajp.amjpathol.org). $n=5$ to 12 mice per group. B: Chimeric mice generated by BMT of Selplg ${ }^{-1-}$, and DKO bone marrow cells were analyzed as described in A. Bars show the relative fraction of Selplg ${ }^{-/-}$and DKO TCR $\beta^{+}$cells in the inflamed ear (inflamed tissue/blood ratios; see Supplemental Figure S7 at http://ajp.amjpatbol.org). $n=5$ mice per group. C: Th1 cells generated in vitro from Selplg ${ }^{-1-}$ and DKO mice were differentially labeled with fluorescent dyes and equal numbers transferred into hyaluronidase-treated recipient wild-type mice 24 hours after challenge with oxazolone. Three hours after transfer, the number of infiltrated Th1 cells was assessed by flow cytometry. Bars represent the fraction of Selplg ${ }^{-1-}$ and DKO cells present in the inflamed ears corrected by the ratio of those initially injected. $n=9$ mice per group. ${ }^{* * *} P<0.01$. All bars represent mean \pm SEM.

in which the migration of Selplg ${ }^{-1-}$ and DKO cells was assessed in the same animals (Figure 6, B and C). Bone marrow cells from Selplg ${ }^{-1-}$ and DKO mice (both Ly5.1) were cotransplanted into wild-type (Ly5.2) recipients, and 2 months later, mice were analyzed for T-cell recruitment into ears inflamed using the DTH model (see Supplemental Figure S7 at http://ajp.amjpathol.org). Compared with Selplg ${ }^{-1-}$, the number of DKO T cells in the inflamed tissue was significantly reduced (Figure 6B). In the second approach, we differentiated in vitro naïve $T$ cells from Selplg ${ }^{-1-}$ and DKO mice into Th1 cells. Cells were then labeled with different fluorescent probes and transferred into wild-type recipients undergoing DTH, which had been treated with hyaluronidase to exclude a contribution of $\mathrm{HA}$ to T-cell migration. Three hours after transfer, the relative frequency of the injected cells in the inflamed ears was analyzed by flow cytometry. Again, there was a reduction in the relative migration of DKO cells (Figure 6C). Together, these experiments demonstrate a physiological role for CD44 in selectin-dependent recruitment of inflammatory $T$ lymphocytes to inflamed areas.

\section{Discussion}

In the present study, we have investigated the contribution of CD44 as a physiological ligand for E-selectin in inflammatory $\mathrm{T}$ lymphocytes. Multiple studies over the last few years have attempted to identify the glycoconju- gates that act as functional ligands for this selectin. These studies were hampered by the poor immunogenicity of these structures and their apparent redundancy. ${ }^{41}$ Only recently has the repertoire of glycoproteins carrying E-selectin ligand activity on murine neutrophils been identified, and shown to consist of three different transmembrane glycoproteins: PSGL-1, ESL-1, and CD44. ${ }^{11}$ We report here that at least two of these, PSGL-1 and CD44, also cooperate to mediate E-selectin binding and adhesion by inflammatory $T$ lymphocytes. Our results suggest a more prominent role for CD44 on T cells compared with neutrophils, which may arise from the differential expression of Fut genes.

The present work complements previous studies regarding the role of CD44 as a receptor for HA on inflammatory $\mathrm{T}$ lymphocytes ${ }^{15-17}$ by showing that E-selectin is also a major functional counterreceptor for this glycoprotein on the inflamed vasculature. The fact that Th1 cells are able to simultaneously bind E-selectin and HA suggests that common posttranslational modifications of CD44, including $\mathrm{N}$-glycosylation, fucosylation, and sulfation $^{42,43}$ are required or at least compatible with these functions. This behavior is analogous to that of neutrophils, which also bind both E-selectin and HA through CD44. ${ }^{10,44}$ Our findings, however, indicate that CD44 engagement of E-selectin has a significant contribution to rolling, arrest, and migration of inflammatory $T$ cells because enzymatic removal of $\mathrm{HA}$ in the absence of PSGL-1 did not significantly alter the arrest efficiencies, rolling velocities, or recruitment to inflamed areas in vivo.

Several recent studies have identified the sialomucin CD43 as a Th1-expressed E-selectin ligand that cooperates with PSGL-1 during Th1 recruitment to inflamed skin..$^{5,7}$ Similar to our findings in $\mathrm{Cd} 44^{-1-}$ mice, single deficiency in CD43 is not sufficient to alter the rolling and in vivo migratory properties of $\mathrm{T}$ lymphocytes, revealing a redundant repertoire of E-selectin ligands. Interestingly, in one of these studies, a second glycoprotein with a molecular weight (100 kDa) compatible with that of hematopoietic CD44 was also shown to mediate rolling on E-selectin. ${ }^{5}$ The low binding activity described for this protein would agree with our observation that CD44 deficiency does not alter the binding of soluble Eselectin to intact Th1 cells. We used a different and previously validated approach ${ }^{10}$ to demonstrate the capacity of CD44 immunopurified from Th1 cells to bind to soluble E-selectin. Our results show that Eselectin binding to CD44 is specific since no binding was found when using a stromal cell line that expresses high levels of CD44.

These data, along with previously published studies, point toward a leukocyte subset-specific repertoire of ligands for E-selectin: whereas PSGL-1 and CD44 appear to contribute to binding activity in both myeloid and T lymphocytes ( ${ }^{6,10,11}$ and the present study), the activity of CD43 appears to be restricted to T lymphocytes ${ }^{5,7,45}$ and that of ESL-1 likely to neutrophils. ${ }^{7,11}$ Moreover, our studies suggest that each of these ligands makes a specialized contribution to the different steps of leukocyte recruitment: both PSGL-1 and CD43 localize to the microvillus projections ${ }^{46,47}$ and are therefore more suitable 
to mediate tethering and initial rolling interactions. ${ }^{5,7}$ In contrast, CD44 is localized on the planar cell body ${ }^{48}$ and might be specialized in later stages by controlling rolling velocities and promoting firm arrest. ${ }^{11}$ The recent observation that CD44 engagement on neutrophils modulates integrin activation through Src-family kinases and p38 further confirms our findings. ${ }^{49}$ The partial or null inflammatory phenotype of mice deficient in PSGL-1, CD43, or CD44 underscores the redundancy of selectin ligands and the highly specialized contribution of each of them during T-cell-mediated inflammation. The exact contribution of these ligands to E-selectin-mediated rolling and, more importantly, whether they account for all physiological ligand activity on inflammatory $T$ cells remain open questions that will require the generation of mice deficient in all possible combinations of these glycoproteins ${ }^{50}$. It should also be noted that surface glycolipids might also contain a significant fraction of the E-selectin binding activity present on human leukocytes. ${ }^{39,51,52}$

Induction of the Fut7 gene, a process coordinated by the transcription factor T-bet in Th1 cells, ${ }^{53}$ has been recognized as a rate-limiting step for the generation of functional selectin ligands on inflammatory leukocytes. Fut7 is similarly important for the synthesis of E-selectin ligands on myeloid cells, but in these cells Fut4 also makes a significant contribution.,24 Although the exact physiological targets of each of these enzymes are not well characterized, in vitro studies have demonstrated the preferential fucosylation of PSGL-1 by Fut7 and of ESL-1 and glycolipids by Fut4. Recent studies have further demonstrated that expression of Fut7 is sufficient to confer E-selectin binding capacity to CD44. ${ }^{39,40,54}$ In line with these findings, our expression analyses indicate that, compared with neutrophils, Th1 cells express very low levels of Fut4, whereas Fut7 expression is similar. This, together with the observation that cell arrest is differentially controlled by CD44 in Th1 cells and by ESL-1 in neutrophils ( ${ }^{11}$ and this study), suggests a different repertoire of E-selectin ligands between these leukocyte subsets. Analysis of the function of ESL-1 on inflammatory lymphocytes will be required to further support this contention.

In summary, our study expands knowledge about the receptors involved in inflammatory processes by identifying the specialized roles of CD44 as an E-selectin ligand on inflammatory $T$ cells. Our results suggest the intriguing possibility that different combinations of E-selectin ligands function on myeloid and inflammatory $T$ cells, and that this could originate from the differential expression of fucosyltransferase genes. Further work to identify these ligands and the enzymatic activities involved in their generation may allow the design of drugs to differentially interfere with the accumulation of certain damaging inflammatory leukocytes, while still allowing the clearance of undesired pathogens.

\section{Acknowledgments}

We thank Yoshio Katayama, Rodger McEver, Daniel Lucas, Christoph Scheiermann, Olga Barreiro, and Ana Urzainqui for comments on the manuscript, and Simon
Bartlett for English editing. We also thank Angel Ayuso, Anna Peired, Andrea Martín, and Florent Ghinoux for their technical support.

\section{References}

1. Kupper TS, Fuhlbrigge RC: Immune surveillance in the skin: mechanisms and clinical consequences. Nat Rev Immunol 2004, 4:211-222

2. Ley K, Kansas GS: Selectins in T-cell recruitment to non-lymphoid tissues and sites of inflammation. Nat Rev Immunol 2004, 4:325-335

3. Weninger W, Ulfman LH, Cheng G, Souchkova N, Quackenbush EJ, Lowe JB, von Andrian UH: Specialized contributions by alpha(1,3)fucosyltransferase-IV and FucT-VII during leukocyte rolling in dermal microvessels. Immunity 2000, 12:665-676

4. Xie H, Lim YC, Luscinskas FW, Lichtman AH: Acquisition of selectin binding and peripheral homing properties by CD4(+) and CD8(+) T cells. J Exp Med 1999, 189:1765-1776

5. Alcaide P, King SL, Dimitroff CJ, Lim YL, Fuhlbrigge RC, Luscinskas FW: The 130-kDa glycoform of CD43 functions as an E-selectin ligand for activated Th1 cells in vitro and in delayed-type hypersensitivity reactions in vivo. J Invest Dermatol 2007, 127:1964-1972

6. Hirata T, Merrill-Skoloff G, Aab M, Yang J, Furie BC, Furie B: P-selectin glycoprotein ligand 1 (PSGL-1) is a physiological ligand for E-selectin in mediating $\mathrm{T}$ helper 1 lymphocyte migration. J Exp Med 2000, 192:1669-1676

7. Matsumoto M, Shigeta A, Furukawa Y, Tanaka T, Miyasaka M, Hirata $\mathrm{T}$ : CD43 collaborates with P-selectin glycoprotein ligand-1 to mediate E-selectin-dependent T cell migration into inflamed skin. J Immunol 2007, 178:2499-2506

8. Xia L, Sperandio M, Yago T, McDaniel JM, Cummings RD, PearsonWhite S, Ley K, McEver RP: P-selectin glycoprotein ligand-1-deficient mice have impaired leukocyte tethering to E-selectin under flow. $\mathrm{J}$ Clin Invest 2002, 109:939-950

9. Dimitroff CJ, Lee JY, Rafii S, Fuhlbrigge RC, Sackstein R: CD44 is a major E-selectin ligand on human hematopoietic progenitor cells. J Cell Biol 2001, 153:1277-1286

10. Katayama Y, Hidalgo A, Chang J, Peired A, Frenette PS: CD44 is a physiological E-selectin ligand on neutrophils. J Exp Med 2005, 201: 1183-1189

11. Hidalgo A, Peired AJ, Wild MK, Vestweber D, Frenette PS: Complete identification of E-selectin ligands on neutrophils reveals distinct functions of PSGL-1, ESL-1, and CD44. Immunity 2007, 26:477-489

12. Aruffo A, Stamenkovic I, Melnick M, Underhill CB, Seed B: CD44 is the principal cell surface receptor for hyaluronate. Cell 1990, 61:1303-1313

13. Jalkanen S, Jalkanen M: Lymphocyte CD44 binds the $\mathrm{COOH}$-terminal heparin-binding domain of fibronectin. J Cell Biol 1992, 116:817-825

14. Weber GF, Ashkar S, Glimcher MJ, Cantor H: Receptor-ligand interaction between CD44 and osteopontin (Eta-1). Science 1996, 271:509-512

15. Bonder CS, Clark SR, Norman MU, Johnson P, Kubes P: Use of CD44 by CD4+ Th1 and Th2 lymphocytes to roll and adhere. Blood 2006, 107:4798-4806

16. DeGrendele HC, Estess P, Picker LJ, Siegelman MH: CD44 and its ligand hyaluronate mediate rolling under physiologic flow: a novel lymphocyte-endothelial cell primary adhesion pathway. J Exp Med 1996, 183:1119-1130

17. DeGrendele HC, Estess $P$, Siegelman MH: Requirement for CD44 in activated T cell extravasation into an inflammatory site. Science 1997, 278:672-675

18. Mohamadzadeh $M$, DeGrendele $H$, Arizpe $H$, Estess $P$, Siegelman $M$ : Proinflammatory stimuli regulate endothelial hyaluronan expression and CD44/HA-dependent primary adhesion. J Clin Invest 1998, 101:97-108

19. Zarbock A, Lowell CA, Ley K: Spleen tyrosine kinase Syk is necessary for E-selectin-induced alpha(L)beta(2) integrin-mediated rolling on intercellular adhesion molecule-1. Immunity 2007, 26:773-783

20. Wang HB, Wang JT, Zhang L, Geng ZH, Xu WL, Xu T, Huo Y, Zhu X, Plow EF, Chen M, Geng JG: P-selectin primes leukocyte integrin activation during inflammation. Nat Immunol 2007, 8:882-892

21. Hidalgo A, Chang J, Jang JE, Peired AJ, Chiang EY, Frenette PS Heterotypic interactions enabled by polarized neutrophil microdomains mediate thromboinflammatory injury. Nat Med 2009, 15: $384-391$ 
22. Lowe JB: Glycosylation in the control of selectin counter-receptor structure and function. Immunol Rev 2002, 186:19-36

23. Knibbs RN, Craig RA, Natsuka S, Chang A, Cameron M, Lowe JB, Stoolman LM: The fucosyltransferase FucT-VII regulates E-selectin ligand synthesis in human T cells. J Cell Biol 1996, 133:911-920

24. Homeister JW, Thall AD, Petryniak B, Maly P, Rogers CE, Smith PL, Kelly RJ, Gersten KM, Askari SW, Cheng G, Smithson G, Marks RM, Misra AK, Hindsgaul $O$, von Andrian UH, and Lowe JB: The alpha(1,3)fucosyltransferases FucT-IV and FucT-VII exert collaborative control over selectin-dependent leukocyte recruitment and lymphocyte homing. Immunity 2001, 15:115-126

25. Hidalgo A, Ma S, Peired AJ, Weiss LA, Cunningham-Rundles C, Frenette PS: Insights into leukocyte adhesion deficiency type 2 from a novel mutation in the GDP-fucose transporter gene. Blood 2003 101:1705-1712

26. Austrup F, Vestweber D, Borges E, Lohning M, Brauer R, Herz U, Renz H, Hallmann R, Scheffold A, Radbruch A, Hamann A: P- and E-selectin mediate recruitment of T-helper-1 but not T-helper-2 cells into inflamed tissues. Nature 1997, 385:81-83

27. Catalina MD, Estess $P$, Siegelman $M H$ : Selective requirements for leukocyte adhesion molecules in models of acute and chronic cutaneous inflammation: participation of $\mathrm{E}$ - and $\mathrm{P}$ - but not L-selectin. Blood 1999, 93:580-589

28. Chong BF, Murphy JE, Kupper TS, Fuhlbrigge RC: E-selectin, thymus- and activation-regulated chemokine/CCL17, and intercellular adhesion molecule-1 are constitutively coexpressed in dermal microvessels: a foundation for a cutaneous immunosurveillance system. J Immunol 2004, 172:1575-1581

29. Auffray C, Fogg D, Garfa M, Elain G, Join-Lambert O, Kayal S, Sarnacki S, Cumano A, Lauvau G, Geissmann F: Monitoring of blood vessels and tissues by a population of monocytes with patrolling behavior. Science 2007, 317:666-670

30. Norman MU, Hulliger S, Colarusso P, Kubes P: Multichannel fluorescence spinning disk microscopy reveals early endogenous CD4 T cell recruitment in contact sensitivity via complement. J Immunol 2008, 180:510-521

31. Chiang EY, Hidalgo A, Chang J, Frenette PS: Imaging receptor microdomains on leukocyte subsets in live mice. Nat Methods 2007, 4:219-222

32. Doebis C, Siegmund K, Loddenkemper C, Lowe JB, Issekutz AC, Hamann A, Huehn J, Syrbe U: Cellular players and role of selectin ligands in leukocyte recruitment in a T-cell-initiated delayed-type hypersensitivity reaction. Am J Pathol 2008, 173:1067-1076

33. Kunkel EJ, Ley K: Distinct phenotype of E-selectin-deficient mice E-selectin is required for slow leukocyte rolling in vivo. Circ Res 1996 79:1196-1204

34. Matsumoto M, Atarashi K, Umemoto E, Furukawa Y, Shigeta A, Miyasaka M, Hirata T: CD43 functions as a ligand for E-Selectin on activated T cells. J Immunol 2005, 175:8042-8050

35. Avigdor A, Goichberg P, Shivtiel S, Dar A, Peled A, Samira S, Kollet O, Hershkoviz R, Alon R, Hardan I, Ben-Hur H, Naor D, Nagler A, Lapidot T: CD44 and hyaluronic acid cooperate with SDF-1 in the trafficking of human CD34+ stem/progenitor cells to bone marrow. Blood 2004, 103:2981-2989

36. Issekutz AC, Issekutz TB.: The role of E-selectin, P-selectin, and very late activation antigen-4 in T lymphocyte migration to dermal inflammation. J Immunol 2002, 168:1934-1939

37. Atarashi K, Hirata T, Matsumoto M, Kanemitsu N, Miyasaka M: Rolling of Th1 cells via P-selectin glycoprotein ligand-1 stimulates LFA-1-mediated cell binding to ICAM-1. J Immunol 2005, 174:1424-1432
38. Clissi B, D’Ambrosio D, Geginat J, Colantonio L, Morrot A, Freshney NW, Downward J, Sinigaglia F, Pardi R: Chemokines fail to upregulate beta 1 integrin-dependent adhesion in human Th2 T lymphocytes. J Immunol 2000, 164:3292-3300

39. Huang MC, Laskowska A, Vestweber D, Wild MK: The alpha $(1,3)$ fucosyltransferase Fuc-TIV, but not Fuc-TVII, generates sialyl Lewis X-like epitopes preferentially on glycolipids. J Biol Chem 2002, 277 : $47786-47795$

40. Huang MC, Zollner O, Moll T, Maly P, Thall AD, Lowe JB, Vestweber D: P-selectin glycoprotein ligand-1 and E-selectin ligand-1 are differentially modified by fucosyltransferases Fuc-TIV and Fuc-TVII in mouse neutrophils. J Biol Chem 2000, 275:31353-31360

41. Varki A: Selectin ligands: will the real ones please stand up? J Clin Invest 1997, 99:158-162

42. DeGrendele HC, Kosfiszer M, Estess P, Siegelman MH: CD44 activation and associated primary adhesion is inducible via T cell receptor stimulation. J Immunol 1997, 159:2549-2553

43. Maiti A, Maki G, Johnson P: TNF-alpha induction of CD44-mediated leukocyte adhesion by sulfation. Science 1998, 282:941-943

44. McDonald B, McAvoy EF, Lam F, Gill V, de la Motte C, Savani RC, Kubes P: Interaction of CD44 and hyaluronan is the dominant mechanism for neutrophil sequestration in inflamed liver sinusoids. J Exp Med 2008, 205:915-927

45. Woodman RC, Johnston B, Hickey MJ, Teoh D, Reinhardt P, Poon BY, Kubes P: The functional paradox of CD43 in leukocyte recruitment: a study using CD43-deficient mice. J Exp Med 1998 , 188:2181-2186

46. Moore KL, Patel KD, Bruehl RE, Li F, Johnson DA, Lichenstein HS, Cummings RD, Bainton DF, McEver RP: P-selectin glycoprotein ligand-1 mediates rolling of human neutrophils on P-selectin. J Cell Biol 1995, 128:661-671

47. Yonemura S, Nagafuchi A, Sato N, Tsukita S: Concentration of an integral membrane protein, CD43 (leukosialin, sialophorin), in the cleavage furrow through the interaction of its cytoplasmic domain with actin-based cytoskeletons. J Cell Biol 1993, 120:437-449

48. von Andrian UH, Hasslen SR, Nelson RD, Erlandsen SL, Butcher EC A central role for microvillous receptor presentation in leukocyte adhesion under flow. Cell 1995, 82:989-999

49. Yago T, Shao B, Miner JJ, Yao L, Klopocki AG, Maeda K, Coggeshall KM, McEver RP. E-selectin engages PSGL-1 and CD44 through a common signaling pathway to induce integrin \{alpha\} $\{$ beta\}2mediated slow leukocyte rolling. Blood 2010, 116:485-494.

50. Yago T, Fu J, McDaniel JM, Miner JJ, McEver RP, Xia L: Core 1-derived O-glycans are essential E-selectin ligands on neutrophils. Proc Natl Acad Sci U S A 2010, 107:9204-9209

51. Alon R, Feizi T, Yuen CT, Fuhlbrigge RC, Springer TA: Glycolipid ligands for selectins support leukocyte tethering and rolling under physiologic flow conditions. J Immunol 1995, 154:5356-5366

52. Nimrichter L, Burdick MM, Aoki K, Laroy W, Fierro MA, Hudson SA, Von Seggern CE, Cotter RJ, Bochner BS, Tiemeyer M, Konstantopoulos K, Schnaar RL: E-selectin receptors on human leukocytes. Blood 2008, 112:3744-3752

53. Chen GY, Osada H, Santamaria-Babi LF, Kannagi R: Interaction of GATA-3/T-bet transcription factors regulates expression of sialyl Lewis $X$ homing receptors on Th1/Th2 lymphocytes. Proc Natl Acad Sci U S A 2006, 103:16894-16899

54. Barthel SR, Wiese GK, Cho J, Opperman MJ, Hays DL, Siddiqui J, Pienta KJ, Furie B, Dimitroff CJ: Alpha 1,3 fucosyltransferases are master regulators of prostate cancer cell trafficking. Proc Natl Acad Sci U S A 2009, 106:19491-19496 